\section{GERTRUDIS GÓMEZ DE AVELLANEDA EN SEVILLA: ILUSIONES Y CENIZAS DE UN PERIPLO LITERARIO}

\author{
María Caballero Wangüemert \\ Universidad de Sevilla \\ mcaballero@us.es
}

Cómo citar este artículo/Citation: Caballero Wangüemert, M. (2014). "Gertrudis Gómez de Avellaneda en Sevilla: ilusiones y cenizas de un periplo literario". Arbor, 190 (770): a181. doi: http://dx.doi.org/10.3989/arbor.2014.770n6002

Recibido: 12 febrero 2014. Aceptado: 30 octubre 2014.

RESUMEN: En mi acercamiento a Tula en las páginas que siguen, quiero partir de una afirmación: Sevilla marcó un antes y un después en su vocación literaria entre 1838 y 1840, dándose a conocer en los periódicos como poeta. Las cartas a Cepeda, su primer y apasionado amor, son hoy el documento más interesante de esta etapa, tanto desde el punto de vista autobiográfico como metaliterario. Aun así, todas las obras de esta época pueden leerse en clave autobiográfica. Tras una fecunda trayectoria literaria, culminará en Sevilla su carrera profesional mientras prepara sus obras completas. Está viuda, prematuramente envejecida y cansada. Sus restos reposan hoy en el sevillano cementerio de San Fernando. Este trabajo, que bucea en los años sevillanos de la cada vez más afamada escritora, pretende ser un homenaje en el bicentenario de su nacimiento.

PALABRAS CLAVE: Gertrudis Gómez de Avellaneda; Sevilla; Literatura romántica XIX; mujer; pasión; religiosidad.

\section{GERTRUDIS GÓMEZ DE AVELLANEDA IN SEVILLA: ILLUSIONS AND ASHES OF A LITERARY TOUR}

Copyright: (c) 2014 CSIC. Este es un artículo de acceso abierto distribuido bajo los términos de la licencia Creative Commons Attribution-Non Commercial (by-nc) Spain 3.0.
ABSTRACT: This paper shows an approach to Tula. I start from a statement: Sevilla marked a before and after in his literary vocation between 1838 and 1840, becoming known in the newspapers as a poet. Letters to Cepeda, her first and passionate love, are today the most interesting document of this period, both from the point of view metaliterary and autobiographical. All the works of this period can be read as autobiographical plays. After a prolific literary career, Sevilla will be the city where she ends her career while she prepares her complete works. She is a widow, prematurely aged and tired. Her remains now rest in Seville's San Fernando cemetery . This work, snorkeling in Seville years of increasingly famous writer, is a tribute to the bicentennial of his birth.

KEYWORDS: Gertrudis Gomez de Avellaneda; Seville; Romantic Literature; XIXth Century; woman; passion; religion. 
Y es que Gertrudis se sintió ligada desde el primer momento con Andalucía. En realidad hay que insistir en el andalucismo de la Avellaneda. Conoce a Andalucía a los 22 años; en periódicos andaluces, con el seudónimo de La Peregrina hace sus primeras salidas editoriales; se deslumbra con su sol [...] todas sus ciudades le gustan [...] y por último se enamora totalmente de Sevilla, a la que se entrega desde muy joven para no olvidarla ya nunca (De las Cuevas, 1954, pp. 57-58).

En mi acercamiento a la Sevilla de Tula a lo largo de las páginas que siguen, quiero partir de una afirmación que, más allá de por quiénes sea compartida, hace justicia a los textos de la cubana en sus años de estancia en la capital hispalense. Sevilla marcó un antes y un después en la trayectoria de quien, veinteañera aún y recién llegada de su Cuba transatlántica, se asentará en esta ciudad y cuajará en ella su vocación literaria. Hablamos de un período corto pero fecundo (1838-1840) en que se abrirá paso como mujer deslumbrante y escritora en ciernes: en Sevilla recibirá los primeros cortejos y las primeras lisonjas "profesionales", dándose a conocer en los periódicos. Paradójicamente y cerrando el círculo de una ya fecunda trayectoria literaria, en Sevilla culminará su carrera profesional. Al final de los sesenta, viuda, prematuramente envejecida y cansada, retornará de la Cuba que la vio nacer para recalar junto a parientes y amigos en una geografía amable. Se inicia el declive de una vida apasionante: está enferma, se siente sola y atemorizada, escribe poco, los admiradores parecen haberse eclipsado. Quedan algunos jóvenes fascinados por su leyenda, como el futuro padre Coloma. El salto a Madrid será breve: morirá y será enterrada en la sacramental de San Martín rodeada de un pequeño séquito. iVanitas vanitatis! No obstante y según sus últimas voluntades, sus restos reposan hoy en el seviIlano cementerio de San Fernando, donde aguardan la resurrección de la carne.

Uno podría preguntarse: ¿por qué fue Sevilla el destino de esta inquieta cubana? Gracias a sus cartas editadas desde 1907 conocemos su trayectoria vital, su infancia feliz en Puerto Príncipe respaldada por un padre consentidor y al que adoraba. Después, el trauma de su pérdida cuando solo contaba nueve años. Y el doble trauma del posterior matrimonio de la madre con Escalada, un padrastro al que no aceptará... los deseos de escapar, viajar a la metrópoli para conocer la estirpe paterna. Es verdad que hay razones "intelectuales" más profundas: la isla se le queda corta a esta nueva Corinne, que se sabe superior y desea abrirse paso en la metrópoli. Siempre tuvo un apoyo en su hermano Manuel y ahora (estamos en el 36) lo convence para realizar el ansiado viaje. Arrastra a la familia y tras un atormentado viaje transatlántico muy bien estudiado por Albin (2002) y fructífero en cuanto que comienza sus cuadernillos de viaje en molde epistolar a la prima y querida amiga Eloísa, y cuaja sus primeras poesías impelida por la magnitud de la naturaleza y sus lecturas de Heredia, arriba a Burdeos. Por cierto que la estudiosa citada centra muy bien esa primera escritura híbrida de la cubana:

Alego que la complejidad de estas Memorias radica en que pueden ser leídas como un diario de viajes, como un comentario socio-político, y como una narración personal y autobiográfica que está permeada por una meditación poética (Albin, 2002, p. 30).

Aparco por conocida y fácil de reconstruir en su Memoria la decepcionante estancia gallega, con parientes (los Escalada) que no comprenden a la doctora y amantes que se le declaran (es el fatum, el tributo que debe pagar a su belleza espectacular por exótica y tropical). En esas circunstancias, no es extraño que haya vuelto los ojos a los parientes paternos de Constantina, una amable ciudad de la sierra norte sevillana a donde se dirigirá con Manuel en mayo del 38. Estancia breve, porque la ciudad acogedora no tiene la vida cultural que Tula anhela. En junio del 38 ya están en Sevilla, donde se instalarán con la familia que les alcanza. Se inicia una vida social perceptible, si bien con cuentagotas, en las cartas a Cepeda: amistades, paseos, teatros, ópera y tertulias donde ial fin! florecerán sus inquietudes literarias.

De todo ello da buena cuenta a su prima y, andando el tiempo, algo se escurrirá entre líneas en su correspondencia con Cepeda, el amor de su vida... un amor frustrado y nunca a su altura, como es bien sabido. Las descripciones de Cádiz y Sevilla (la ciudad, los monumentos, las costumbres...) irán paulatinamente siendo sustituidas por la vida misma: lecturas poéticas que arroban a sus admiradores, no acostumbrados a la excelente modulación de la fascinante jovencita... Publicaciones bajo el seudónimo de La Peregrina en periódicos gaditanos (La Aureola), granadinos ( $L a$ Alhambra) o sevillanos (El Boletín de Teatros, El Sevillano, El Cisne...). Tula sabe ganarse a los hombres: así por ejemplo, en el verano del 39 se acerca unos días a Cádiz para conocer a D. Manuel Cañete, director de $L a$ Aureola. Y aprovecha para saludar a un veraneante, D. Alberto Lista, profesor de Humanidades en el madrileño colegio de San Mateo que, poco después, le abrirá las puertas del Ateneo y el Liceo literario de la capital. Tal vez de este viaje arranque también el conocimien- 
to del famoso pintor Moral, a quien se debe uno de sus retratos más famosos, una preciosa miniatura.

No todo son frivolidades. Trabaja incansablemente en una novela comenzada en su viaje hacia el Viejo Mundo, la futura Sab, que publicará en Madrid en el 41, junto a sus Poesías. Asimismo, se arriesgará con su primera obra dramática, Leoncia, estrenada en Granada en 1840 con un cierto éxito que se repetirá en Sevilla, Valencia, Cádiz y Madrid, a pesar de los defectos estructurales propios de una principiante. De hecho, nunca la incluyó en sus Obras Completas.

¿Fue el triunfo que permitía avizorar otros mayores en la capital? ¿O fueron los desdenes del "tibio galán" que resultó Cepeda lo que impulsó a la cubana a instalarse en Madrid? Sea como fuere y de la mano de Lista y Nicasio Gallego, la Avellaneda triunfará en un Madrid cortesano al que llegó junto a su hermano a fines del 40 , cuando irrumpe el romanticismo. La dejaremos presentándose de incógnito en el Liceo literario de los Duques de Villahermosa, para pedir leyera sus versos en público a un Zorrilla que, tiempo después, revivirá así el episodio:

Subí a la tribuna y leí como mejor supe unas estancias endecasílabas que arrebataron al auditorio. Rompiose el incógnito y, presentada, por mí, quedó aceptada en el Liceo, y por consiguiente en Madrid, como la primera poetisa de España, la hermosa cubana Gertrudis Gómez de Avellaneda (Zorrilla, 1882, p. 131).

Volvamos atrás: ¿Qué huellas quedan de Sevilla en los textos de Tula? ¿Hasta qué punto contribuyó a cuajar su vocación literaria y a redondear su personalidad la ciudad del Guadalquivir?

\subsection{Sevilla según la "Memoria" o Cuadernos de viaje a su prima Eloísa de Arteaga y Loynaz}

De la mano de Figarola-Caneda recuperamos hoy la Memoria de viaje... En barco, vía Lisboa llega a Cádiz junto a su hermano el once de abril del 38. Deslumbramiento y desembarco... Cádiz es la ciudad hembra que se pasea aspirando sus fragancias. No importa cuánto den de sí monumentos concretos como la catedral:

Yo en mi entusiasmo nada vi, nada; vi a Cádiz, vi la ciudad de Cádiz toda en conjunto, linda, esbelta, coqueta y seductora [...]. Yo confieso, Eloísa, mi pasión y parcialidad por esta ciudad (Figarola-Caneda, 1929, p. 274).

Por fin el diecisiete toman el vapor Península a Sevilla. Un mes y medio en la ciudad antes de partir a visitar a su tío paterno, Felipe Gómez de Avellaneda, en Constantina, da la medida de lo que será su nuevo centro. Pasados tres meses y huyendo del consabido pretendiente rico que siempre se le declara, se instala definitivamente en la ciudad del Guadalquivir. Antes de poetizar sus calles y ciudades, las describirá dentro del epígrafe "Sevilla" del cuadernillo tercero, en el que fija el tiempo de la escritura ("Siete meses han cursado después de aquel día") suficientes para ir calibrando el empaque y señorío de la hermosa ciudad del Betis, a la que inevitablemente compara con Cádiz:

Se levanta, altiva y majestuosa, como una reina, coronada de sus gigantescos edificios. No presenta, ciertamente, la vista risueña de Cádiz; su aspecto es noble e imponente, y tal cual corresponde a su antigüedad e inmemorial grandeza (Figarola-Caneda, 1929, p. 275).

Es decir, le rinde tributo, pero no cae rendida a sus plantas con la empatía demostrada con la tacita de plata. Castro y Calvo, en su completo estudio que sirve hoy de prólogo a las obras completas publicadas en la B.A.E., compara estas páginas con las de otros autores que se extasiaron ante la ciudad del Betis. Tal vez olvida que Tula se mueve en un texto de ámbito privado, la carta, sin pretensiones literarias, pero aún así... la distancia entre esta somera descripción y las bellas páginas dedicadas por los viajeros a la mítica Sevilla es muy grande, como se deduce por sus palabras:

Heredia ha dedicado a Sevilla muy bellas páginas en el prólogo a Bernal Díaz. ¿Lo conocía Tula? Alfieri y Merimée hablaron del hechizo de sus cantos, la inquietud de sus bandoleros, como siglos anteriores Cervantes y Mateo Alemán descubrieron la picaresca...

Bécquer nos ha dejado una de las más bellas páginas sobre Sevilla, que acaso no leyó la Avellaneda: Sevilla con su Giralda de encajes, que copian temblando el Guadalquivir, y sus calles morunas, tortuosas y estrechas"... (Gómez de Avellaneda, 1974, p. 45).

Es cierto que la intencionalidad incide sobre el texto y que en este siglo la distancia entre público y privado es casi insalvable. Aún así, la comparación no suele favorecer a la joven escritora. Aconsejo al lector interesado la lectura de un libro coetáneo, Sevilla y Andalucía, de Antoine Latour, quien fue corresponsal de Fernán Caballero y destina páginas memorables (capítulos III al XIII) a la capital hispalense en la bella edición de Renacimiento (2006). La ciudad se encarna en una historia tejida de leyendas que, a su vez, cobran vida en la cotidianeidad de sus habitantes...

Tula no tiene esos objetivos a la vista. Da cuenta de forma escueta y a modo de sumario narrativo 
del marco geográfico en que su vida se desarrolla. Por ello, a continuación y en el mismo epígrafe que veníamos comentando, pasa a describir la gran ciudad en torno a cien mil habitantes, los tres arrabales (Macarena, Triana y San Bernardo), la muralla árabe, los puentes de barcas... y se detiene en la fisonomía de cuatro calles del centro. Un dédalo "arabesco" de "calles angostas y torcidas"... casas "irregulares y sin embargo deliciosas" con su "encantador patio" que "exhala mil purísimos aromas"... "flores, fuentes, aguas", auténtica fruición en este ardiente clima". La joven poeta demuestra una singular sensibilidad y se abandona al encanto; pero ello no le impide establecer comparaciones entre su Puerto Príncipe y la capital del Betis, al modo de los viajeros de todo tiempo y lugar. Porque el destinatario lo exige: debe saber, conocer, calibrar... y para ello es necesario comparar.

La casa y sus habitaciones, la plaza del Duque, paseo de los elegantes... El epistolario a Cepeda alude a él una y otra vez; y saltando alternativamente de las páginas de la Memoria a este último, obtenemos una vívida y completa impresión de lo que fue la vida cotidiana de la Avellaneda en este periodo de esplendor exuberante en verano; tristón a fines de septiembre. Aunque dirá corrigiéndose:

[...] no, Eloísa, no es así: mi aversión al invierno me hace injusta. Sevilla es siempre seductora, y ni los vientos, ni las lluvias, ni las nieblas tristurosas que acompañan a esta estación de muerte, pueden oscurecer enteramente su sol brillante y su puro cielo (Figarola-Caneda, 1929, p. 277)

Y continúa, marcando el tiempo del relato: “Aún gozamos aquí, no obstante que escribo estas líneas el 4 [sic] de diciembre, días muy bellos y noches apacibles (Figarola-Caneda, 1929, p. 278).

Al hablar del estado del tiempo se desencadena una asociación de ideas que la transporta arrobada al Caribe. Nueva cronista de Indias, focaliza su evocación desde la mirada colombina (aún sin nombrar explícitamente al Almirante) reescribiendo el tópico de la eterna primavera que caracteriza la región:

¡Feliz, empero, el país privilegiado donde reina un eterno verano y cuyos árboles jamás ha osado el invierno despojar de sus galas! iFeliz Cuba, nuestra cara Patria, y feliz tú, Eloísa, que no has conocido otro cielo que el suyo! [...] ¡Oh Patria! ¡Oh, dulce nombre, que el destierro solo enseña a apreciar! ¡Oh, tesoro que ningún tesoro puede reemplazar!... Yo he visto los trémulos rayos del sol reflejar en su golfo, yo he paseado su margen encantadora, yo he respirado su ambiente puro... y el cielo de otros países no es cielo para mí. Volvamos a Sevilla (Figarola-Caneda, 1929, p. 278).

¡La imitadora de Heredia según Albin (2002, pp. 77-104), la hija dilecta de una Cuba aún colonia española, vibra con la emoción y añoranza del exilado! Algunos críticos no han dejado de señalar la paradoja: desde el punto de vista político, la patria no existe, no puede existir para esta hija de funcionario español que, además apostó por la metrópoli en la que quiere y conseguirá triunfar como poeta y dramaturga. Pero el XIX es un siglo romántico y nacionalista, donde el exilio propicia poemarios encendidos. Por eso, y por las deudas reconocibles con su maestro (él sí exilado), elabora esa imagen romántica y herediana del yo en vía hacia el destierro.

Retornemos a Sevilla, así de modo abrupto, de la mano de Gertrudis. ¿Cómo no considerar una gran ciudad aquella que posee más de veinte plazas, el paseo de las Delicias, el magnífico salón del Cristina, el teatro principal y sobre todo el célebre Alcázar, al que por cierto escribe un poema que tampoco superó la criba de las obras completas? ¿Qué importa que las calles estén mal empedradas, que el número de coches no llegue ni a la mitad de Puerto Príncipe, si uno puede perderse por los salones y jardines de un Alcázar a cuya historia alude sin especial interés; más con la que vuelve a vibrar, fundiendo su alma con personajes que se encarnan de nuevo, como Doña María de Portugal, o Don Pedro su hijo, o la hermosa María de Padilla? Las interrogaciones retóricas tan propias de los románticos tiñen un texto que rezuma lirismo por los cuatro costados:

¡Oh, Alcázar! decía yo entre mi, mientras atravesaba sus arabescas salas iCuántos ilustres personajes han pisado tu pavimento! ¡De cuántos secretos has sido depositario! [...]. Revélame, Alcázar, el nombre de tus antiguos poseedores; refiéreme los reyes que has conocido, las fiestas que has presenciado ¡Ay! También habrás sido testigo mudo de grandes sufrimientos... Quizás has servido para sofocar entre tus espesas paredes muchos gemidos (Figarola-Caneda, 1929, p. 280).

La historia hecha carne en el texto desde la empatía femenina, cuya pluma retornará al tono descriptivo para perfilar la Lonja, la Giralda, el patio de los naranjos y la Catedral al modo de una guía turística. La descripción de esta última abre un nuevo cuadernillo, el cuarto, fechado en Sevilla, el ocho de diciembre de 1838. El lector confirma la sospecha al 
leer aquí. "Si quieres una descripción más detallada y completa, Eloísa mía, proporciónate la de Ceán Bermúdez, que es la que me ha servido de guía (como ya te he repetido) al trazar este bosquejo" (FigarolaCaneda, 1929, p. 290).

En resumen: el cuadernillo a Eloísa y por lo que se refiere a Sevilla, combina elementos descriptivos y narrativos... Está entreverado de arranques poéticos teñidos de subjetividad romántica; algo reconocido por la cubana a su prima:

El Patio de los Naranjos despertó mi poesía; me hizo desear ilusiones y hablaba mi corazón cuando tracé en el papel: "illusión celestial! Ante mis ojos/ cayó rasgado tu fulgente velo/ $Y$ una tierra pisé llena de abrojos/ En vez de blando y satinado suelo" (Figarola-Caneda, 1929, p. 286).

Son versos del tercer cuarteto de "A la ilusión", fechado en 1840 e incluido en la primera edición de sus Poesías (1841); si bien lo desechó para las del cincuenta y sesenta y nueve, tal vez por su excesivo retoricismo ornamental. Por cierto, que de ese volumen y por lo que se refiere a la capital andaluza solo salvó para la posteridad su poema "Paseo por el Betis" (Gómez de Avellaneda, 1974, pp. 247248), una instantánea pictórica del amanecer sobre el río, en metro breve y ritmo ligero. Se acentúan los aromas de la majestuosa ciudad "perfumada de azahar" mientras el hablante lírico queda extasiado ante el paisaje enmarcado en simbología clásica (Ledo) y un vocabulario con reminiscencias orientalistas (auras, zafir, arrebol) propias de los viajeros románticos. El poema se abre así: "Ya del Betis/ Por la orilla/ Mi barquilla/ Libre va. / Y las auras/ Dulcemente/ Por mi frente/ Soplan ya. / iBoga, boga, / Buen remero/ Que el lucero/ Va a salir. / Y a Occidente/ Ledo sube/ En su nube/ De zafir!" (Gómez de Avellaneda, 1974, p. 247).

El cuadernillo se cierra con la visita al cementerio de Sevilla que no encuentra tan romántico como el de Bordeaux, aunque es "vasto y aseado"... Le aburre la "igualdad monótona y uniforme"... "ningún sepulcro sobresale más que otro" -dirá (Figarola-Caneda, 1929 , p. 292). La incansable Tula anuncia una visita a Itálica y a Constantina, para que su prima amada pueda compartir las vivencias. Y concluye: "Es Sevilla una ciudad histórica, grande, clásica, rica de monumentos y recuerdos, que parece mejor y más bella cuanto más se la mira y examina" (Figarola-Caneda, 1929, p. 292).

\subsection{De las cartas autobiográficas a la autobiografía fingida: recepción y reescritura de la "Autobiografía y cartas a Cepeda" (1907/1914)}

En ese proceso se embarca Tula mientras se enamora, lo que da lugar a otra de sus más grandes obras literarias, las cartas a Cepeda, que se publican muchos años después de su muerte. No es mi deseo profundizar en su estudio que tiene fortísimos valedores (Kirkpatrick, 1991; Torras, 2003; Rodríguez Gutiérrez, 2012). Pero considero necesario citarlo ahora como literatura testimonial, epistolario romántico por excelencia y, tal vez, el legado más interesante para la posteridad en cuanto que perfila (¿construye?) la aventura vital y literaria de la Avellaneda.

Milena Rodríguez, en su documentado artículo ataca de frente el problema textual: no conocemos los manuscritos de ese cuadernillo, a partir del cual y por encargo de María Govantes, viuda de Cepeda, afirma Lorenzo Cruz-Fuentes haber arrostrado el trabajo editorial. No suele recordarse que hizo dos versiones (1907 y 1914). La segunda va "enriquecida" con trece cartas que se entremezclan con las existentes, sin mucha explicación por parte del editor quien, además, se atreve a suprimir párrafos o alterar, entre otras cosas, un uso peculiar de las comas que confiere personalidad al texto de Tula... "¿Qué autoridad se concede a sí mismo el editor para atreverse a alterar ese estilo?" -se pregunta con irritada razón la doctora Rodríguez (2012, p. 51)-. Y concluye apostando por el lado de la moral o el cuidado de la imagen para la famosa pareja:

Se ha acusado a menudo a Lorenzo Cruz de Fuentes de proteger a Cepeda frente a Gómez de Avellaneda, debido a la amistad que unió a los dos hombres. Sin embargo, consideramos que Cruz de Fuentes no sólo protegió a Cepeda, sino que intentó, además, cuidar la imagen de la escritora [...]. Se trata de cuestiones asociadas con la moral o creencias religiosas y lo suprimido contiene un elemento que podía resultar perturbador en la época en la que se editan las cartas, por lo cual creemos que no se trata de inofensivos, casuales errores del editor o de la imprenta [...]. El editor se convirtió, también, en censor (Rodríguez Gutiérrez, 2012, p. 54).

¡La cita es demasiado larga, pero tan sabrosa! No hay más que decir. Hay que ser sumamente prudentes en la lectura de este epistolario, porque ha sido "trabajado" previamente por el editor. Aún más por el suyo el Diario de amor (Gómez de Avellaneda, 1928), auténtico fraude (vende como inéditas cartas ya publicadas y las manipula a su antojo) que Cotarelo y Rodríguez Gutiérrez desenmascaran. Pero esas cuestiones reba- 
san los límites cronológicos que nos hemos impuesto. No así el estudio de la gestación, por otra parte muy conocida. Ya Lazo había advertido años atrás de que hay como dos partes en este "elegía de un amor imposible" (Lazo, 1972, p. 72) en la que interviene la pasión amorosa y lo demás. Retornaremos a la pasión, pero centrémonos de momento en lo demás: una mujer de talento, amiga del saber, de certera agudeza y serena imparcialidad y madurez de criterio transmite sus recuerdos de infancia y primera juventud; así como las impresiones sobre la vida cotidiana en Sevilla: los paseos del Duque, la ópera, la rutina, las tertulias y cotilleos. Incluso sus lecturas y entretenimientos... Enfrente, la pasión; se enamora desbocadamente y... "todo se poematiza" (Lazo, 1972, p. 71). Puede formarse toda una colección de poemas en prosa a partir del texto -sigue diciendo el crítico-. De ahí -concluyela envolvente ambigüedad en pro de elevar al objeto amoroso y las estrategias para alcanzar por caminos nuevos al imperturbable amante.

Kirkpatrick insistirá en su tesis de la escritura como acto de seducción a Cepeda; tesis más que sostenible porque se está escribiendo el yo para otro, casi a pedido, como hacían las monjas con sus confesores. Por cierto que varios trabajos relacionan a Tula con Sor Juana (Sabat de Rivers, 1981, pp. 99-110; Torras, 2003, pp. 13-59) por otra parte inevitable. El de esta última repasa la bibliografía anterior dialogando con ella de forma sistemática: ¿estamos ante un documento de verdad, producto de una jovencita ingenua y enamorada, como aseguraron en su día Eugenio Suárez Galván (1980, pp. 281-296) y otros? O "la intencionalidad y el tono, determinada por la relación con el receptor, establecen claras diferencias entre los dos", como concluye Sergio Beser en el prólogo a la edición del Círculo de Lectores (1996, p. 22), al comparar este cuadernillo (privado) con los cuatro cuadernillos de Memorias a Eloísa (también privados, de hecho no se publicaron hasta 1914). Incluso con unos Apuntes autobiográficos (1850), redactados por la autora para la revista madrileña La Ilustración, es decir, de ámbito público. Porque curiosamente no coinciden, a pesar de haber sido redactados en un breve lapso de tiempo. El destinatario rige la escritura hasta el punto de modificar las perspectivas del relato.

Y por aquí desembocamos en una interpretación opuesta a la "sinceridad romántica" para una autobiografía construida y calculada al milímetro: es lo que demuestra Meri Torras en su trabajo, paso a paso, cotejando el texto con las circunstancias y constatando que "Tula, el yo autobiográfico de Gertrudis Gómez de Avellaneda, bebe a grandes tragos de la literatura romántica" (Torras, 2003, p. 37), mientras reinventa los corresponsales y juega con ellos, especialmente Cepeda, basculando entre ofrecimientos de amor y amistad. En la recta final (y no me detengo en analizarlo porque eso ya ha sido suficientemente estudiado) monta toda una estrategia retórica en torno a la duda entre quemarlo o entregarlo a su destinatario. Mera estrategia: ella ya ha decidido:

Gertrudis Gómez de Avellaneda conocía el valor de lo que había firmado. Ese texto epistolar no está escrito para ella misma, el papel del interlocutor es primordial y sin Ignacio de Cepeda el texto -ya lo advertí- carece de sentido. Por eso la cubana siguió el impulso de su corazón pero también de su cabeza cuando entregó el cuadernillo al sevillano. Y sabía muy bien lo que hacía (Torras, 2003, p. 59).

¿Sorprenderá entonces que en nuestro siglo se hayan escrito autobiografías ficticias de la escritora como las Memorias de una mujer libre (2008), de Cira Andrés y Mar Casado?

\subsection{Poesías (1841), Leoncia (drama, 1940) y Sab (novela, 1841) como textos autobiográficos}

Gertrudis es poeta por excelencia, una poeta que andando el tiempo abrirá incluso perspectivas al modernismo por su experimentación con la métrica y el verso. Edith Checa escribió en 2001 un artículo colgado hoy en la red sobre la escritura periodística de la cubana, donde se cita un primer poema publicado en "El Cisne" de Sevilla. Lamentablemente su interesante trabajo de rescate, no alude a publicaciones de la etapa sevillana. De hecho existen pocas referencias a poemas concretos y la mayoría no perduraron en sus obras completas, por lo que no abordaré su estudio y remito al interesante portal que se le dedica en el Cervantes. Pero conviene recordar que se está gestando en Sevilla, al hilo del día a día, una de las grandes poetas del romanticismo. Su poesía intimista, amorosa, con enclaves históricos... irá incrementando el tema religioso, presente desde los orígenes de modo convencional, hasta convertirlo en una vivencia intensa y faceta primordial de su poesía.

Por lo que se refiere a la dramaturga, el seis de junio y el ocho de noviembre respectivamente se estrena en Sevilla y Granada Leoncia, drama que adolece de defectos como obra primeriza, pero bien recibida por la crítica en su momento. Su protagonista es una mujer ultrajada y abandonada, tema que obsesionará a Tula: "Hay como un vaticinio del futuro de la Avellaneda. Parece anunciar el porvenir, y las 
exclamaciones de Leoncia, inventadas por la autora, leídas hoy con mirada retrospectiva, pueden aplicarse a su vida" (Bravo-Villasante, 1986, p. 55). El texto fue inteligentemente desechado por la autora a la hora de preparar sus obras completas.

En cuanto a su novela Sab, empieza a escribirla en el viaje y la terminará en la capital hispalense. Desde tiempo atrás viene celebrándose como una de las primeras novelas abolicionistas o antiesclavistas por su temprana fecha (1841) y el mensaje tan claro. Es la tesis, entre muchos otros, de Ilia Casanova-Marengo en su libro, Ruptura y mediación en la narrativa antiesclavista cubana (2002). Una segunda reelectura en clave de género sirvió para relanzarla desde los woman studies. Desde esta perspectiva y en su monografía El discurso de Gertrudis Gómez de Avellaneda: identidad femenina y otredad, Brígida Pastor afirma que existe "una analogía entre la condición femenina y la esclavitud, tema que se construye más explícitamente en su otra novela temprana, Dos mujeres y en otras obras posteriores" (Pastor, 2002, p. 97). Algo que ha sido aceptado y repetido; incluso se insiste en que la esclavitud del matrimonio es peor que la suerte del esclavo quien al menos teóricamente podría cambiar de amo. Así el libro sería tanto un desafío al sistema patriarcal, como a los límites discursivos del lenguaje.

Relacionando este asunto con el epígrafe anterior donde se pondera la manipulación textual de la autobiografía, me parece más que interesante el rescate de párrafos dentro de ella que son prácticamente idénticos a otros de $S a b$, (a saber, unas líneas del parlamento del mulato a Teresa). El asunto demuestra al menos dos cosas: que Tula es escritora siempre, también cuando supuestamente escribe una carta privada para ser leída por un único destinatario: su amado Cepeda. La segunda, aún más importante para el taller de escritura en que se va forjando el estilo de la cubana, respondería a la pregunta que se hace Milena Rodríguez: “¿Gómez de Avellaneda mezcla a conciencia su escritura personal y su escritura literaria?" (Rodríguez, 2012, p. 56). Y aconseja prudencia.

Ya Kirkpatrick (1991, p. 151) había aventurado que en esta novela la cubana distribuye su propia intimidad entre varios personajes (Sab, Teresa, Carlota), según temas y situaciones dramáticas. Y Carmen Bravo-Villasante (1986) había ido mucho más lejos al postular esta novelita como "literatura de pasión", "una novela preciosa para el romanticismo español" [...] "nuestro Atala romántico" (p. 66). Y rechaza la militancia abolicionista en quien -según ella- no se había significado en absoluto en esta línea:
No obstante los alegatos contra la esclavitud, no tiene sentido comparar la novela de Sab con La cabaña del tío Tom de H. Becher Stone, pues no se propuso la Avellaneda hacer algo semejante, sino pintar la pasión de naturalezas de fuego y los amores contrariados e imposibles. En Sab el elemento abolicionista es lo de menos (Bravo-Villasante, 1986, p. 71).

Tesis muy fuertes y controvertidas por el aparente conservadurismo de su propuesta. En las décadas pasadas postular la denuncia, bien fuera maltrato femenino o esclavitud irredenta, estaba mucho más en consonancia con la directrices sociales y literarias. Pasado el tiempo y asumidas estas lecturas ¿podrían ser compatibles con una relectura en clave parcialmente autobiográfica? Es lo que quisiera plantear aquí, considerando que la novela por momentos adopta "el mismo tono de sus memorias y de sus cartas autobiográficas, una experiencia inolvidable desdoblada en género epistolar y en ficción novelesca" (Bravo-Villasante, 1986, p. 69). No es momento de profundizar en mi tesis, bucear en textos que lo justifiquen... Pero tiene una cierta lógica. Sevilla fue punto de arranque y broche final de su vida literaria. $Y$ no solo porque en ella comenzara a escribir sus poesías, dramas y novelas durante la primera estancia; y preparara la edición de sus obras completas y el devocionario en la segunda. Es que sus vivencias autobiográficas cuajan espléndidamente en las obras redactadas en esta ciudad. Más allá del afamado cuadernillo a Cepeda, que siempre se consideró así, habría que releer Leoncia, Sab, algunas poesías y el devocionario desde esta perspectiva. $Y$ enmarcarlas en un romanticismo que primaba la autenticidad de la pasión (amorosa, religiosa) hasta límites estrafalarios. Esta tesis no descarta el taller de escritura, la manipulación textual propia de una mujer que siempre quiso ser literata.

\section{LA SEGUNDA ESTANCIA SEVILLANA: ELABORANDO LA POSTERIDAD}

El 21 de mayo de 1864 embarca para España junto a su fiel hermano Manuel. Un alto de dos meses en Nueva York para visitar las cataratas del Niágara, donde el poema es obligado. Pero su prodigiosa vena lírica parece haberse agotado. A su regreso al Madrid de sus tiempos juveniles lleva sólo una poesía en recuerdo de Heredia, el cantor del Niágara. Su salud está más quebrantada que nunca, por lo que decide instalarse en Sevilla durante cuatro años. Recupera amigos, veranea en Puerto Real, donde pasea la alta sociedad, escribe Catilina (1867)... y un Devocionario nuevo y completísimo en prosa y verso (1867), para 
el que toma como base el redactado en el 47, que creía perdido. En realidad se dedica a organizar sus Obras Completas, que saldrán entre 1869 y 1871 en cinco tomos, mientras entabla amistad con Fernán Caballero, mayor que ella pero que la sobrevivirá. Su religiosidad se acrecienta.

Está avejentada y su tristeza crece con la enfermedad y muerte de Manuel, el hermano querido. Tras regalar a la universidad y la Biblioteca colombina sus Obras... ( no en vano ha desarrollado un fuerte sentido de autoría, que le lleva a dejar fuera Sab, Dos mujeres, Leoncia, Guatimozin...) volverá como viuda a Madrid donde, enferma de diabetes, morirá olvidada de casi todos el uno de febrero del 73.

Su relación con Fernán Caballero fue trabajada hace muchos años por Jesús de las Cuevas en un artículo publicado en Archivo Hispalense (De las Cuevas, 1954, pp. 51-72) bajo el título "Tula y Fernán en Sevilla a través de unas cartas inéditas". El artículo da mucho más de lo que promete: hace un recorrido por los epistolarios de la Avellaneda desde su llegada a Andalucía, nombrando el Diario de amor editado por Ghiraldo (sic) (1928) y el libro de Figarola-Caneda (1929) ya comentados. Lo hace para señalar rasgos de estilo que arrancan de la primera juventud: "claridad dentro de la necesaria brevedad y sinceridad a raudales" (De las Cuevas, 1954, p. 53). Siempre muy expresivas, a veces se tiñen de tristeza o desaliento, paradójicamente tan propias de la juventud y de las altas horas de la noche en que redacta sus misivas. Las de los últimos tiempos siguen describiendo "el paseo de por la tarde en Sevilla, junto al Guadalquivir, retrata con su gracejo espontáneo la sociedad sevillana en Puerto Real, o nos emociona al verla sola en una casa de la ciudad" (De las Cuevas, 1954, p. 53).

Por lo que se refiere a Fernán, todavía en 1859 declaraba no conocerla personalmente, aunque la considera "inspirada artista", "dueña de un alma muy elevada" y de "un hermoso corazón". Ahora, en 1869 se dirige a ella como "ilustre Fernán", "sincera amiga"... Le dedica El príncipe de Viana y le envía el Devocionario Nuevo y Completísimo. Por su parte, la Caballero en carta a Latour se expresa así:

Extrañará a Ud si le digo que somos muy amigas la Avellaneda y yo, por ser, al parecer, nuestras sendas muy opuestas, así como nuestros caracteres. Esto probará que no es preciso asemejarse para quererse. Es una mujer buenísima, aunque yo quisiera, para su propia felicidad, su sangre corriese menos apresurada y su espíritu se elevase menos a esas regiones tan altas que, aunque bellas y puras, tienen la contra de que en ellas se pierden de vista las cosas terrenas y la senda que hemos de pisar para nuestro bienestar y conveniencia (De las Cuevas, 1954, p. 64).

La extrañeza no sobra: hubo quienes, como Angélica Palma, la hija del escritor peruano, pensaban que en Fernán había "admiración, simpatía y despego" hacia la que denominaba "la Magna”, en referencia a su santa. Son muy distintas, una rica y otra casi pobre; una, lanzada y otra precavida y conservadora; Tula, exuberante y Cecilia "fea, precavida y no le gusta relacionarse con muchas personas" (Alzaga, 1997, p. 186). Aun así, tienden puentes.

Sea como fuere y fruto de esta segunda estancia sevillana, se conservan más de seis cartas de Tula a Gonzalo Segovia (conde de Segovia, hijo) de 1866, a quien cuenta de su vida y a veces solicita pequeños favores. Por ellas sabemos que monta a caballo (siempre le apasionaron), va a Puerto Real a veranear con la flor y nata de la sociedad sevillana y, progresivamente (mucho más tras la muerte del hermano) se encierra en una casona con criados de los que desconfía; incluso pide una pistola, hasta tal punto recela de posibles asaltos. Testimonio de la vida cotidiana de quien ya va de vuelta tras haber deslumbrado años atrás a la sociedad española.

Alzaga en un gráfico sumario describe así esta etapa:

Comienza a preparar sus Obras literarias. Corrige, reescribe. La soledad y el dolor paralizan su creación. Desde su abandono nuevamente se refugia en Dios; crece en la fe; intenta rehacer el Manual del cristiano escrito entre 1846 y 1847 , a raíz de la muerte de Sabater, perdido por la casa editora "La Publicidad"; y da a la imprenta el Devocionario nuevo y completísimo en prosa y verso en 1867 (Alzaga, 1997, p. 69).

Años atrás ya Cotarelo había sido reticente respecto de estas correcciones. Y su biógrafa Carmen Bravo-Villasante es particularmente crítica con la labor emprendida por Tula en estos momentos: "alguna vez el cambio es acertado -dice-, pero la mayoría de las veces la corrección es perturbadora, totalmente inútil. Incapaz de crear cosas nuevas, es como si quisiera tener la sensación de crear corrigiendo los originales" (Bravo-Villasante, 1986, p. 197). Un juicio bastante despiadado, en cualquier caso. Carezco de la autoridad y preparación suficientes para contradecir un juicio al menos osado. Sea como fuere, porque no está tan segura o..., imprime pocos ejemplares (sabe lo que es y su destino) hasta el punto de haberse convertido en una joya bibliográfica (hay 
un ejemplar en el ICl madrileño). Por delante, lo que Alzaga denomina "invierno y muerte" (Alzaga, 1997, p. 194): el 68 con la Gloriosa, la revolución y huida de la reina, el cambio de gobierno... todo un recambio generacional, el fin de una era. Tula se siente desamparada sin sus protectores, los reyes y los Duques de Montpensier. Además, el diez de octubre estalla en Cuba una de las secuelas, la denominada "guerra de los diez años". Todo tristezas para quien se enfrenta a la recta final. ¿Extrañará entonces que se refugie cada vez más en una religión presente como motivo desde sus primeras poesías ("A la Virgen", "Dios y el hombre")? En su desarreglada vida ya atisbó que la felicidad proviene de la conjunción de amor y virtud. Incluso en su novela primeriza Dos mujeres ya se intuían esos derroteros. Es el momento de asumir esa pasión, de cuyos excesos se arrepintió tantas veces y sublimarla a lo divino.

En conclusión: de este repaso por los años sevillanos de Gertrudis Gómez de Avellaneda se desgaja una imagen más integrada, aunque compleja y contradictoria de la mujer y la escritora. Si la bibliografía historicista tradicional la enfocó como "una mujer travestida de hombre que quiso triunfar en la metrópoli" y la recuperación feminista de las últimas décadas del siglo veinte como "la Corinne cubana", es decir, la mujer superior abocada a la infelicidad amorosa, un acercamiento más ponderado desde los primeros tiempos andaluces podría desembocar en una visión más global de las incongruencias vitales (amantes tumultuosos frente a matrimonios tradicionales) y literarias (Sab, Dos mujeres, con sus denuncias abolicionistas y propuestas de emancipación femenina, por un lado, frente a devocionarios y poesías religiosas que se extienden de la juventud a la madurez, en un in crescendo cada vez más personal, por otro). La Avellaneda -como dijeran Raimundo Lazo y Carmen Bravo-Villasante- fue una mujer romántica, acendradamente romántica por formación y carácter-diría yo- y eso explica los excesos, las alternativas radicales entre orgullo y pasión, entre razón y fe. Es un Lope de Vega redivivo, una mujer de su época. Y se ha forjado en el catolicismo. El trabajo de Florinda Alzaga recupera esa faceta, en apariencia extemporánea si la enfocamos desde los prismas feministas del pasado siglo. Tiene mucho de Beauvoir en su recelo del matrimonio y la trampa que supone para la mujer con aspiraciones intelectuales; pero no es una agnóstica o atea al uso. Es cierto que su carácter irá templando con la edad y los sinsabores de la vida, y su religiosidad acendrándose en la recta final; lo que le permite integrar facetas en origen aparentemente contradictorias del epistolario, de ciertas novelas, de sus devocionarios y poesías... Y podrá hacerlo porque su trayectoria siempre tuvo un hilo conductor: la búsqueda del ideal, llámese amor humano, triunfo intelectual o Dios.

\section{BIBLIOGRAFÍA}

Albin, M. C. (2002). Género, poesía y esfera pública. Gertrudis Gómez de Avellaneda y la tradición romántica. Madrid: Trotta.

Alzaga, F. (1997). La Avellaneda: intensidad y vanguardia. Miami: Universal.

Andrés, C. y Casado, M. (2008). Gertrudis Gómez de Avellaneda: memorias de una mujer libre. Madrid: Icaria.

Bravo-Villasante, C. (1967/1986). Una vida romántica: la Avellaneda. Madrid: Edhasa.

Casanova-Marengo, I. (2002). El intersticio de la colonia. Ruptura y mediación en la narrativa antiesclavista cubana. Madrid/Frankfurt: Iberoamericana/ Vervuert.

De las Cuevas, J. (1954). Tula y Fernán en Sevilla a través de unas cartas inéditas. Archivo Hispalense, 20, pp. 51-72.
Figarola-Caneda, D. (1929). Gertrudis Gómez de Avellaneda: biografía, bibliografía e iconografía, incluyendo muchas cartas inéditas o publicadas, escritas por la gran poetisa o dirigidas a ella, y sus memorias. Madrid: Sociedad General Española de Librería.

Kirkpatrick, S. (1991). Feminización del sujeto romántico en la narrativa: Gómez de Avellaneda. En: Las románticas. Escritoras y subjetividad en España, 18351850. Madrid: Cátedra/Feminismos Universidad de Valencia: Instituto de la Mujer, pp. 131-164.

Gómez de Avellaneda, G. (1928). Diario de amor: obra inédita. Madrid: Aguilar.

Gómez de Avellaneda, G. (1974). Obras de doña Gertrudis Gómez de Avellaneda (Biblioteca de Autores Españoles). Madrid: Ediciones Atlas.
Gómez de Avellaneda, G. (1989). Poesías y epistolario de amor y de amistad. Madrid: Castalia.

Gómez de Avellaneda, G. (1907/1996). Autobiografía y cartas. Huelva: Diputación de Huelva.

Gómez de Avellaneda, G. (1996). Autobiografía. Barcelona: Círculo de Lectores.

Gómez de Avellaneda, G. (1997). Sab. Madrid: Cátedra.

Latour, A. (2006). Sevilla y Andalucía (Estudios sobre España). Sevilla: Renacimiento.

Lazo, R. (1972). Gertrudis Gómez de Avellaneda. La mujer y la poetisa lírica. México: Porrúa.

Pastor, B. (2002). El discurso de Gertrudis Gómez de Avellaneda: identidad femenina y otredad. Alicante: Universidad de Alicante. 
Rodríguez Gutiérrez, M. (2012). La correspondencia de Gertrudis Gómez de AveIlaneda a Cepeda: problemas en torno a la transmisión del texto. En Entre el cacharro doméstico y la Vía Láctea. Poetas cubanas e hispanoamericanas. Sevilla: Renacimiento, pp. 40-64.

Sabat de Rivers, G. (1981). Sor Juana Inés de la Cruz y Gertrudis Gómez de Avellaneda: dos voces americanas en defensa de la mujer. En Zaldívar, G. (ed.). Home- naje a Gertrudis Gómez de Avellaneda. Miami: Universal, pp. 99-110.

Suárez Galván, E. (1980). La angustia de una mujer indiana o el epistolario autobiográfico de Gertrudis Gómez de Avellaneda. En L'autobiographie dans le monde hispanique. Actes du Colloque International de la Baume-les-Aix. Aixen-Provence: Université de Provence, pp. 281-296.
Torras, M. (2003). Soy como consiga que me imaginéis. La construcción de la subjetividad en las autobiografías epistolares de Gertrudis Gómez de Avellaneda y Sor Juana Inés de la Cruz. Cádiz: Servicio de Publicaciones Universidad de Cádiz.

Zorrilla, José (1882). Recuerdos del tiempo viejo. Barcelona: Imprenta de los Sucesores de Ramírez. 